\title{
Timber under real fire conditions - the influence of oxygen content and gas velocity on the charring behavior
}

\section{Conference Paper}

Author(s):

Schmid, Joachim (1); Santomaso, Alessandro; Brandon, Daniel; Wickström, Ulf; Frangi, Andrea (1)

Publication date:

2016

Permanent link:

https://doi.org/10.3929/ethz-a-010736895

Rights / license:

In Copyright - Non-Commercial Use Permitted 


\title{
TIMBER UNDER REAL FIRE CONDITIONS - THE INFLUENCE OF OXYGEN CONTENT AND GAS VELOCITY ON THE CHARRING BEHAVIOR
}

\author{
Joachim Schmid ${ }^{1}$, Alessandro Santomaso ${ }^{2}$, Daniel Brandon ${ }^{3}$, Ulf Wickström ${ }^{4}$, \\ Andrea Frangi ${ }^{5}$
}

\begin{abstract}
As for any building material, verification of fire resistance is mandatory for timber structures. While nonstandard fire design for steel members has long tradition, the corresponding possibilities for timber members are limited. Reasons for this can be found in the degree of complexity of the material and the limited research done in the field. This paper summarizes outcomes of tests, investigating the influences on the charring behaviour of timber by varying the oxygen content and the gas velocity in the compartment. Results show that charring is depending on the fire compartment temperature, but, results show further that at higher oxygen flow, char contraction was observed affecting the protective function of the char layer. In particular, in the decay phase char contraction should be considered which may have a significant impact to Performance Based Design using non-standard temperature fire curves where the complete fire history including the cooling phase has to be taken into account.
\end{abstract}

KEYWORDS: Timber, Char contraction, Charring, Non-standard fire, Fire resistance

\section{INTRODUCTION AND BACKGROUND}

Fire design of structural timber members is done in Europe according to rules given in the fire part of Eurocode 5, EN 1995-1-2 [1]. Design models specified herein are usually developed for standard fire exposure [2]. Very limited models are available for non-standard fires. In general, design of timber members considers (i) the reduction of the cross-section (CS) by char as well as (ii) the reduction of strength and stiffness of the residual cross-section (RCS). The Reduced Cross-Section Method, or Effective Cross-Section Method addresses (i) by a time depending charring depth and (ii) by a so called zero strength layer. The latter is not content of this study. While the charring rate in standard fires according to ISO 834 or EN 1363-1 [2] is reported to be constant [3], charring rates for non-standard fires varies and existing rules may be questioned.

The origin of this study is based on observations in fire resistance tests following the standard fire exposure

\footnotetext{
${ }^{1}$ Joachim Schmid, ETH Zürich, Chair Timber Structures, Switzerland, schmid@ibk.baug.ethz.ch

${ }^{2}$ Santomaso Alessandro, University of Trieste, Italy santo.alino@gmail.com

${ }^{3}$ Daniel Brandon, SP Wood Building Technology, Sustainable Built Environment, Sweden, daniel.brandon@sp.se
}

(defined time-temperature and pressure curves as well as minimum oxygen content of $4 \%$ [2]) in different furnaces where different charring rates were observed for the same product. An additional motivation for this study is observations of fire accidents where different RCS of solid timber members inside a fire compartment depending on the air flow [4].

\section{TEST PROGRAM}

In total 14 tests with various test conditions were performed in a custom made, gas fired furnace. The tests lasted 60 minutes after ignition. After each test the timber specimen was removed from the furnace and any burning was extinguished with water; this procedure took less than 30 seconds to allow for accurate evaluation of the RCS and the char layer depth.

\subsection{MATERIAL}

Tests were performed with CLT (Cross Laminated Timber) beams (150 mm x $150 \mathrm{~mm}$ x $1730 \mathrm{~mm}, \mathrm{C} 24$

\footnotetext{
${ }^{4}$ Wickström Ulf, LTU, Luleå University of Technology, Sweden, ulf.wickstrom@ltu.se

${ }^{5}$ Frangi Andrea, ETH Zürich, Institute of Structural Engineering, Chair Timber Structures, Switzerland, frangi@ibk.baug.ethz.ch
} 
European wood grade) with $12 \% \pm 1 \%$ equilibrium moisture content. The five layer product (top layer $42 \mathrm{~mm}$ ) is glued with PUR (Polyurethane) adhesive and all specimens were stored in a conditioning room before testing. CLT was used as it was aimed for a homogeneous material with limited number of defects. The timber members with a width of $150 \mathrm{~mm}$ were insulated on both sides with stone wool (initial thickness $45 \mathrm{~mm}$ and density of $35 \mathrm{~kg} / \mathrm{m}^{3}$ ) to evoke one dimensional heat exposure and charring of the surface exposed to fire. In four length positions (CS A to D) the progression of char, temperatures and the oxygen content were recorded during the tests (measurement stations). Temperature measurements were done by means of internal thermocouples type $\mathrm{K}$ with welded junction (wire $\varnothing 3 \mathrm{~mm}$ ) inserted in horizontal bore holes $\varnothing 1.75 \mathrm{~mm}$; wires were inserted so that the first $50 \mathrm{~mm}$ after the hot junction were parallel to the Isotherms.

\subsection{TEST EQUIPMENT}

The equipment used in the tests is shown systematically in Figure 1. The test set-up Figure 2consisted of (i) a gas supply unit in which a defined gas volume and the oxygen content of the supplied gas were controlled by means of mixing ambient air with nitrogen or oxygen, (ii) a heating device where the supply air was mixed with burning Gasol (95\% Propane and $5 \%$ Butane), (iii) a fire compartment (insulated steel channel $200 \mathrm{~mm}$ x $160 \mathrm{~mm}$ x $2000 \mathrm{~mm}$ ) and, (iv) an exhaust unit (part of the fire lab). Three sides of the fire compartment were designed to function as a large plate thermometer (PT) [2] comprising a steel plate at the exposed side and ceramic fibre insulation (double layer in order to address the temperature differences) at the unexposed side. Temperatures were measured at sections $\mathrm{A}$ to $\mathrm{D}$ on the top and side of the fire compartment. Tests were performed in low underpressure (ca. $10 \mathrm{~Pa}$ ) to provide a good working environment in the laboratory. The air velocity was controlled in the inlet (cold condition) as well as in the fire compartment using different measurement techniques, an anemometer as well as a Pitot tube coupled with a temperature measurement [5]. Both measurements were in a reasonable good agreement. The oxygen content of the air was measured with a paramagnetic and an electrochemical method in five CSs, at the beginning of the fire compartment (CS zero) and the sections A to D distributed over the length of the specimen. The sample gas was taken from the compartment by placing the probe head (electrochemical method) and the sample pipe (paramagnetic method) respectively in contact to the timber surface. By means of openings at the side of the probes, the sample gas was taken from distances of about 3 to $10 \mathrm{~mm}$ from the surface.

Data measurements (pressure, temperature, gas velocity, oxygen concentration) were recorded with intervals of 1 to 60 seconds. The gas flow (ambient air, nitrogen, oxygen, Propane) was adjusted manually and the Propane gas flow $(\mathrm{kg} / \mathrm{h})$ was recorded manually when the set point was changed.

\subsection{TEST CONDITION}

All fire tests aimed for a quick initial fire compartment temperature rise and a constant temperature during the test. During the early testing phases, different temperatures of the compartment sections A to D were measured. Additionally to the PT temperature, the gas temperature inside the fire compartment was measured using small thermocouples. The gas temperature was further used to determine the gas velocity in the fire condition in combination with a Pitot tube [5]. The temperatures in the compartment followed an exponential temperature increase, in later phases of each test a temperature plateau between about $700^{\circ} \mathrm{C}$ and $900^{\circ} \mathrm{C}$ was observed.

Gas velocities were varied between about 1 and $15 \mathrm{~m} / \mathrm{s}$ in the fire compartment and the oxygen between 5 and $15 \%$ (percentage by volume). This was accomplished by setting the temperature level by means of the Propane

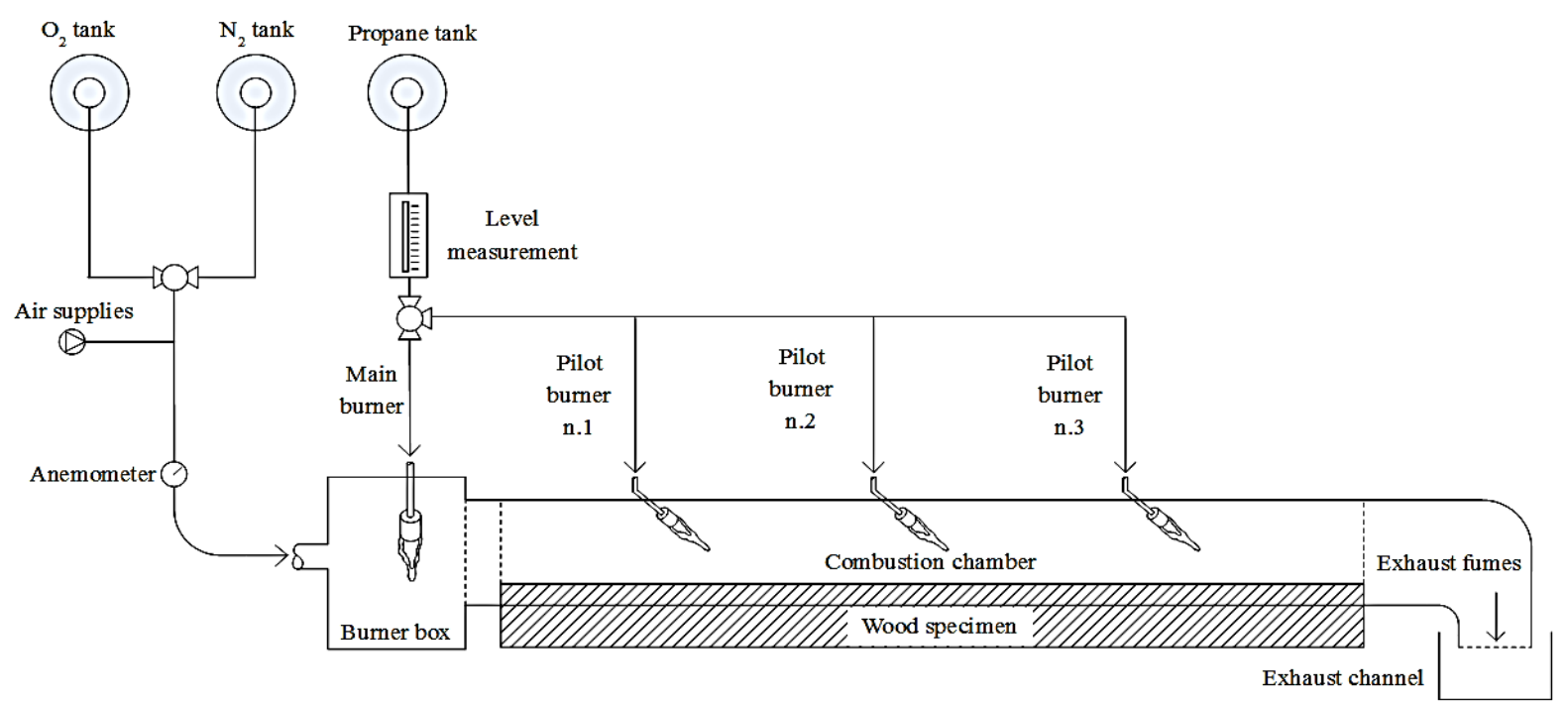

Figure 1: Schematic CS view of the test set-up 
burner at ambient air flow and then adjusting the mixture of ambient air as well as the gases nitrogen and oxygen form the gas tanks in order to reach the set point for the oxygen level together with the gas velocity, see Table 1. This procedure of firing the fire compartment was a looped process.

Table 1: Test program (excluding calibration tests)

\begin{tabular}{llllllllll}
\hline Test & 6 & 7 & 8 & 9 & 10 & 11 & 12 & 13 & 14 \\
\hline Oxygen [\%] & 5 & 15 & 5 & 15 & 15 & 15 & 10 & 15 & 15 \\
\hline $\mathrm{v}[\mathrm{m} / \mathrm{s}]$ & 1 & 10 & 1 & 3 & 3 & 3 & 10 & 10 & 10 \\
\hline Comparison & (a) & (b) & (a) & (b) & & (b) & (c) & (b) & (b) \\
& & (c) & & & & & & (c) & (c) \\
\hline
\end{tabular}

\section{RESULTS}

The documentation comprises the following recordings: (a) gas concentrations, (b) pressure, (c) gas velocity, (d) temperature and (e) documentation of the specimen (RCS, char layer depth) after the tests. For the evaluation of charring depth in longitudinal direction, residual longitudinal-sections at the centre lines of the timber specimens were documented, see Figure 2Error! Reference source not found.

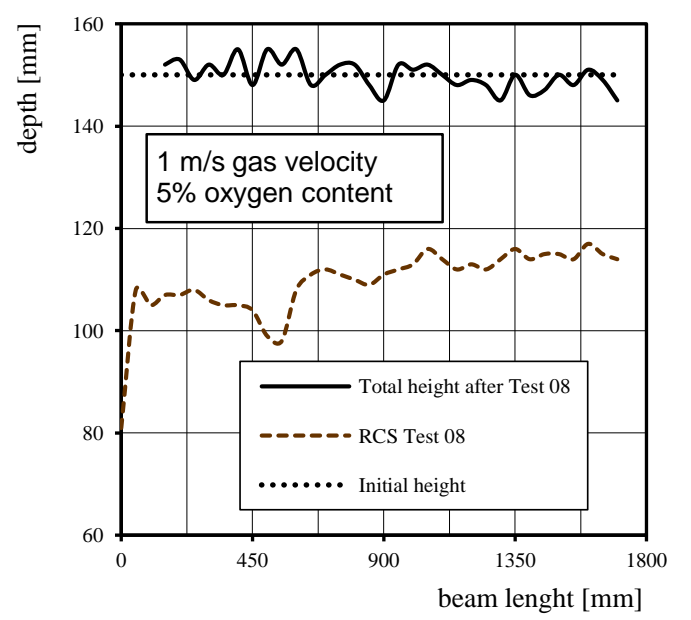

Figure 2: RCS (length profile), and total depth after the fire Test $8\left(1 \mathrm{~m} / \mathrm{s}\right.$ gas velocity, $\left.5 \% \mathrm{O}_{2}\right)$

To evaluate the RCS at the corresponding temperature measurement stations (CS A to D), as well as effects of the limited CS width of the beams, images of the RCS were taken at the measurement stations, see Figure 3.

To follow the progress of charring within the CS during the test the movement of the $300^{\circ} \mathrm{C}$ isotherm, assumed to be equal to the char line [1], was evaluated using the internal thermocouples for all specimens and all sections. The results of the char progression in the corresponding depths of the thermocouples (6 to $42 \mathrm{~mm}$; step +6 ) are presented for Tests 06 and Test 08 (gas velocity of $1 \mathrm{~m} / \mathrm{s}$ and $5 \%$ oxygen content) in Figure 4.

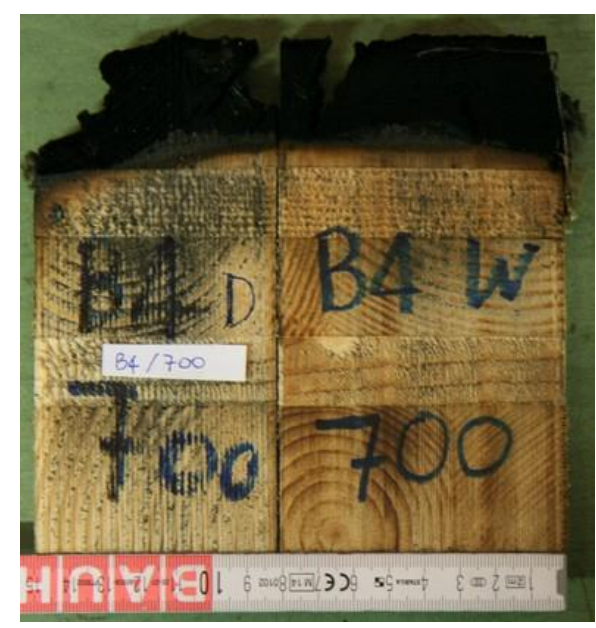

Figure 3: Remaining CS (including the char layer) and residual CS in the length allocated to CS B thermal exposure (measurements at $700 \mathrm{~mm}$ )

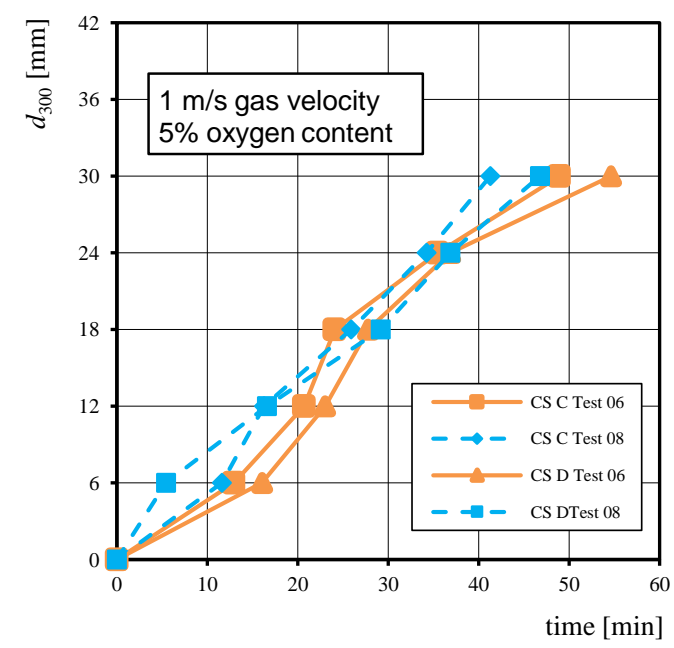

Figure 4: Estimated charring depth by means of the internal thermocouples of Test 6 and 8 in CS C and D.

\subsection{Comparison of test results}

Comparison was done by evaluating test results of similar tests varying one parameter, i.e. (a) the temperature (b) the oxygen content and (c) the gas velocity, see Sections 3.1.1 to 3.1 .3 .

3.1.1 Comparison (a) - Variation of the temperature In Tests 06 and 08 , see Table 1, the gas velocity as well as the oxygen content were set to the same value, $1 \mathrm{~m} / \mathrm{s}$ and $5 \% \mathrm{O}_{2}$. The temperature plateau was deviating as the burner effect was increased in test 08 . In Figure 4 , it is shown that the test done with a higher temperature shows slightly higher charring rates. The difference of the charring rate is $0.12 \mathrm{~mm} / \mathrm{min}$ in CS C and $0.09 \mathrm{~mm} / \mathrm{min}$ in CS D where slightly lower compartment temperatures (PT temperatures) were measured. As a consequence, the RCS was less for higher temperature, although the total CS depth was observed to be about the same, i.e. $150 \mathrm{~mm}$, which means that no char contraction occurred, see Figure 5 . 


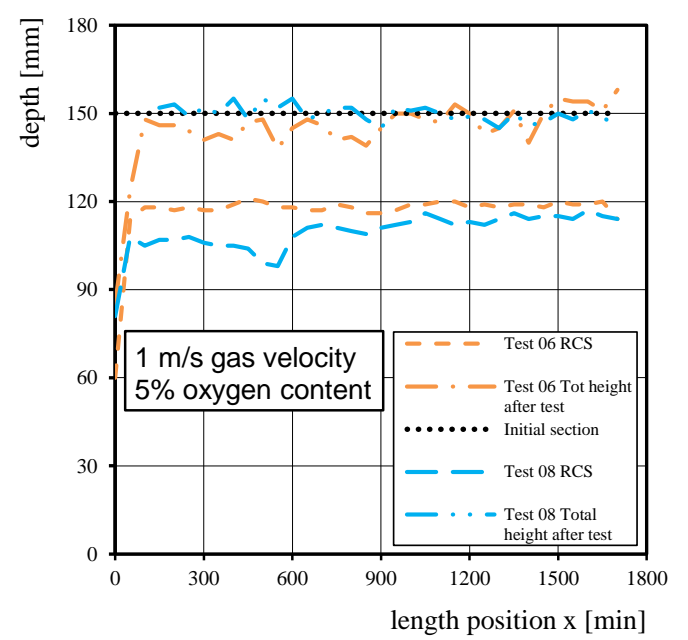

Figure 5: RCS (length profile) and total depth after Tests 06 and Test $08(1 \mathrm{~m} / \mathrm{s}$ gas velocity, $5 \%$ oxygen).

\subsubsection{Comparison (b) - Variation of the gas velocity} The determined charring depth of Test 07, 13 and 14 $(\mathrm{v}=10 \mathrm{~m} / \mathrm{s})$ were compared to Test $09(\mathrm{v}=3 \mathrm{~m} / \mathrm{s})$. All tests within this comparison (b) had an oxygen of $15 \%$. Besides the oxygen content, the temperature was the same for all of the four tests in the steady phase of the temperature-time curve (plateau), compare specifications in Table 1. A difference of $12 \mathrm{~mm}$ thickness in the char layer was observed in CS A comparing the high gas velocity tests and the low velocity test, see Figure 6 . Thus, the maximum difference of the charring rate (in CS A) can be assessed to be about $0.29 \mathrm{~mm} / \mathrm{min}$, see Figure 6 . It was concluded that timber members exposed to (i) high gas velocity and (ii) high oxygen content, i.e. substantial mass flow of oxygen lead to higher charring rates.

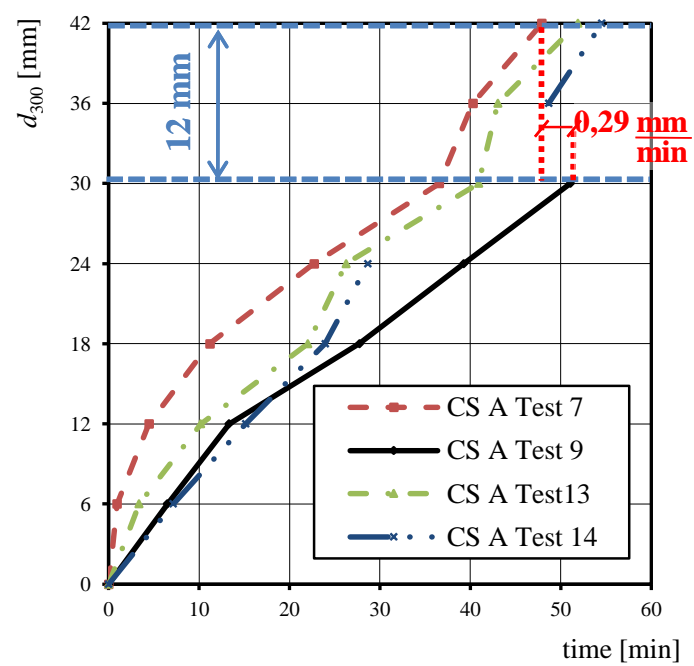

Figure 6: Maximum deviation of the charring depth estimated by means of the internal thermocouples of Test 07, 13, 14 against Test 09 in CS A.

Further, analysis of the RCS showed that the high gas velocity combined with the high oxygen content lead to a reduction of the char layer thickness. This result was more distinct in CS A than at the end of the length profile of the specimen.

\subsubsection{Comparison (c) - Variation of the oxygen content}

In the last comparison, Tests 07,13 and $14\left(\mathrm{O}_{2}\right.$ content $15 \%)$ were compared with Test $12\left(\mathrm{O}_{2}\right.$ content $\left.10 \%\right)$ to study the dependence of the charring rate on the oxygen content. As in the previous comparisons (a) and (b), the other two parameters (in this case gas velocity and temperature) were set to the same value in these tests, see Table 1.

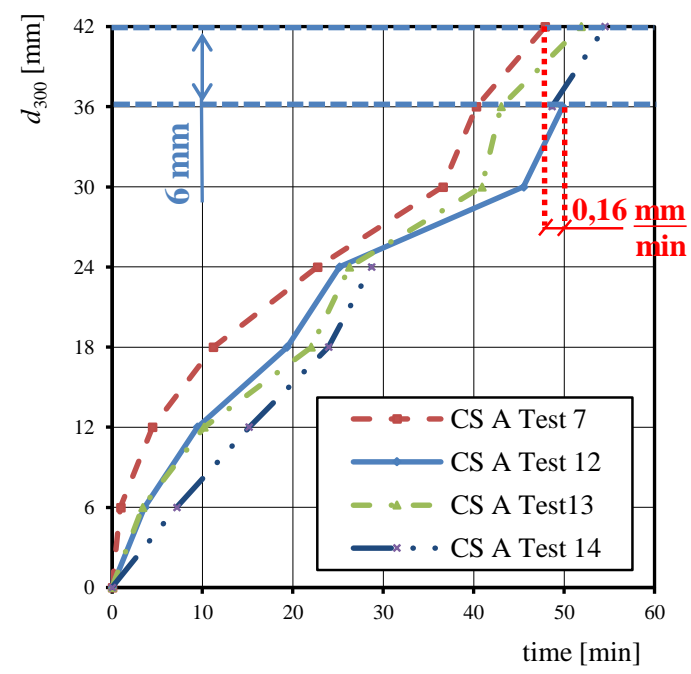

Figure 7: Maximum deviation of the charring depth estimated by means of the internal thermocouples of Test 07, 13, 14 against Test 12 in CS A.

In CS A, as shown in Figure 7, the char layer depth of the high oxygen content tests is $6 \mathrm{~mm}$ larger than for the low oxygen content test.

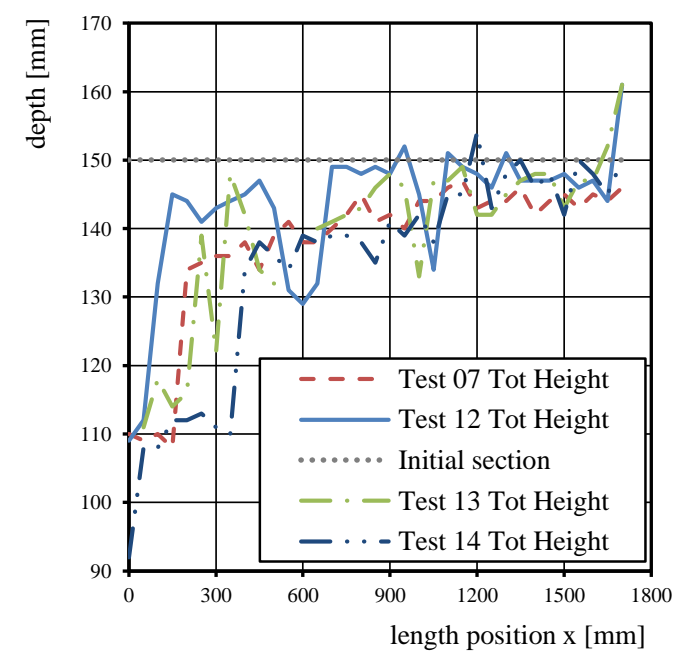

Figure 8: Total depth (length profile) of specimens of Tests 07, 13, 14 against Test 12 in CS A

Thus, also corresponding charring rates are different. This may be traced back to the reduction of the char layer thickness as well as the glowing combustion. Tests with a high oxygen content showed higher charring rates than Test 12. The maximum difference in CS A is $0.16 \mathrm{~mm} / \mathrm{min}$. 
The RCS and the total CS are lower for the tests with a high oxygen percentage (Test 07, 13 and 14) if compared with the low oxygen content test over the entire length of the beam, see also Figure 8.

\section{ANALYSIS OF THE EFFECT OF GAS VELOCITY}

To analyse the effect of gas velocity and/or the mass flow of oxygen, thermal simulations were performed. The aim of the simulations was to estimate the effect of the gas velocity in comparison to temperature on the specimen. In the following, two tests (Test 09 and Test 14) are compared where equal temperature time curves were achieved. The oxygen content was set to $15 \%$ and the gas velocity was 3 and $15 \mathrm{~m} / \mathrm{s}$ respectively. For the simulations it is assumed that the effective material properties for standard fire are valid which are given in [1]. This assumption is justifiable due to the limited deviations of the temperature exposure from the standard fire exposure.

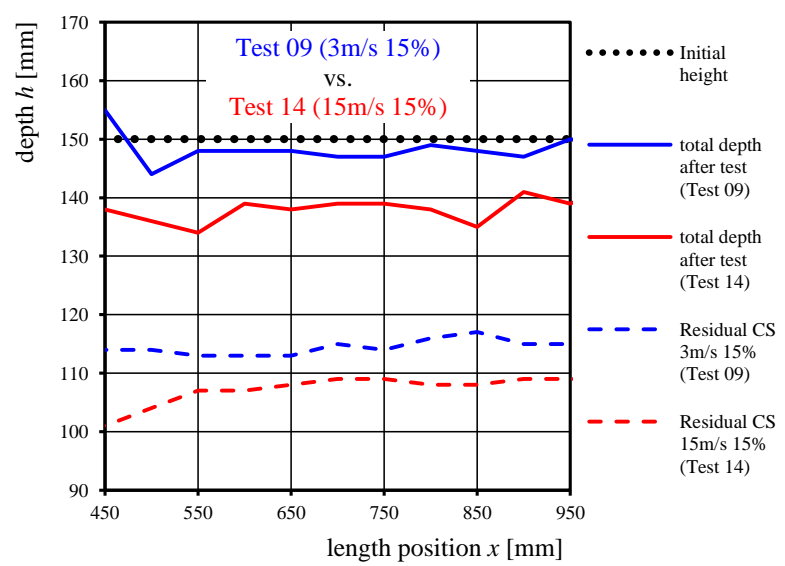

Figure 9: Length profiles of RCS and total depth of specimens of Test 9 and Test 14 in CS A.

As for the other tests, the temperature exposure showed almost a logarithmic temperature rise (ca $30 \mathrm{~min}$ ) up to a plateau at about $800^{\circ} \mathrm{C}$; the tests lasted $60 \mathrm{~min}$. Fire exposures (mean PT temperatures) are specified in Figure 10. Comparison of the specimens after the test showed different CS depths for tests with respect to the total remaining CS (total depth including the char layer) and the RCS (virgin or uncharred wood). The length profile was observed to be most steady in CS B at about $700 \mathrm{~mm}$ length position which is further evaluated. It is assumed that the compartment temperature measurements (PT measurements) of any CS are valid for a length section of about $500 \mathrm{~mm}$. In the following, the RCS and temperature measurements in CS B are further analysed, the corresponding observed profiles of the RCS and the total cross-section depth is given in Figure 9.

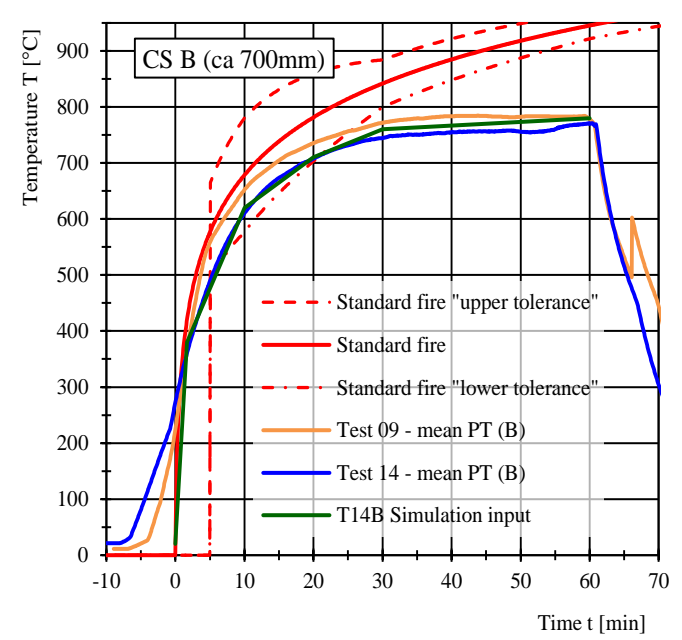

Figure 10: Temperature in tests no. 09 and 14 and the standard fire exposure

\subsection{SIMULATION OF CHAR CONTRACTION}

One dimensional finite element temperature simulations were performed with a section of $1 \mathrm{~mm}$ width. Thermal simulations were performed using the software SAFIR [6]. Standard values for surface emissivity, $\varepsilon=0.8$ and the convective heat transfer coefficients, $\alpha_{\text {un } \exp }=9$ and $\alpha_{\text {exp }}=25 \mathrm{Wm}^{-2} \mathrm{~K}^{-1}$, were used. The sides of the 1-D section were assumed adiabatic and the unexposed side held at $20^{\circ} \mathrm{C}$. Simulations used the effective material properties for density, heat capacity and heat conductivity available in EN 1995-1-2 [1] although this values are intended for standard fire exposure. This approach was found to be reasonable as the deviation of the actual fire exposure from the standard fire temperature time curve is limited, see Figure 11.

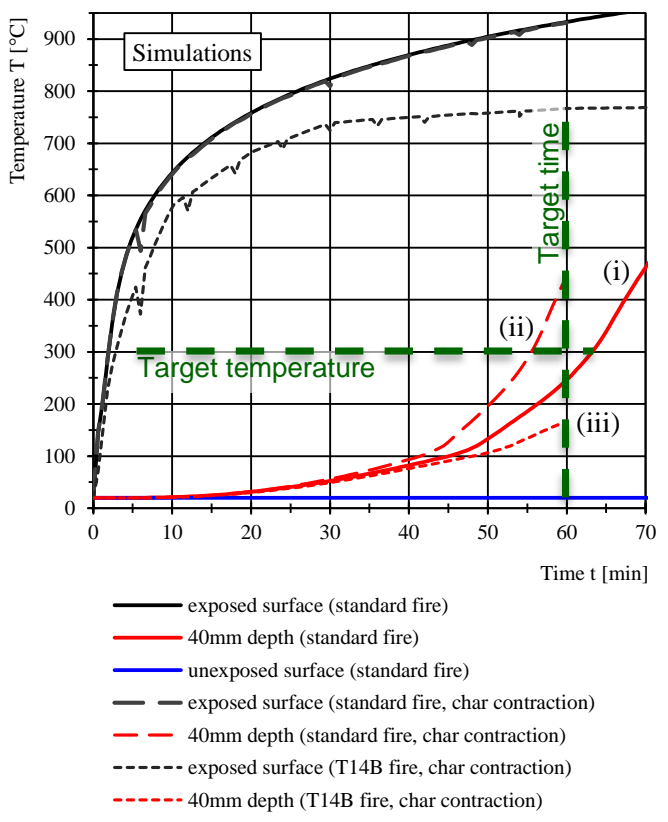

Figure 11: Simulated surface temperatures and temperature at a depth of $40 \mathrm{~mm}$ for different fire exposures with (case (ii) and (iii)) and without (case (i)) char contraction. 
At standard fire exposure, charring depth after one hour can be expected to be about $40 \mathrm{~mm}$ according to the simplified, linear charring rules in [1]; this value is supported by numerous studies. In the following, this depth was used as a reference depth at $60 \mathrm{~min}$, i.e. the temperature rise in $40 \mathrm{~mm}$ depth is analysed with respect to different assumptions to investigate char contraction. In Test 14, char contraction was observed to be about $10 \mathrm{~mm}$ after $60 \mathrm{~min}$.

Char contraction was assumed to occur linearly which was realized in the simulations by deleting elements in equal steps of $6 \mathrm{~min}$. Thus, for simulations, every $6 \mathrm{~min}$ the calculation was stopped, one element (1 mm x $1 \mathrm{~mm})$ deleted and simulations were re-started using the before obtained temperature field for the remaining elements. The following cases were investigated:

(i) Standard fire exposure and no char contraction as basis for the following comparison.

(ii) Standard fire exposure and char contraction to document the importance of the char layer as insulating layer.

(iii) Actual fire exposure and char contraction.

\subsection{SIMULATION RESULTS AND CONCLUSION}

Results for case (i) show lead charring of $40 \mathrm{~mm}$ at about 63 min which is only slightly later than the conservative rules of EN 1995-1-2 [1], see Figure 11. In corresponding fire tests performed in this study, the resultant charring depth was 35 to $38 \mathrm{~mm}$ after $60 \mathrm{~min}$.

Results for case (ii) show that the temperature increase in $40 \mathrm{~mm}$ deviates significantly after $30 \mathrm{~min}$ resulting in charring at this depth about 8 min earlier than in case (i). This indicates that the char layer provides significant protection of the virgin wood in the inner part of the CS. The significance of the char layer has been investigated in many tests with cross-laminated timber where char ablation (e.g. for Cross-Laminated Timber) lead to a significantly increased charring rate.

Results for case (iii) show that considering the slightly lower fire exposure measured in Test 14 charring would not reach $40 \mathrm{~mm}$ depth. This is in contradiction to the observations where the RCS was significantly below $110 \mathrm{~mm}$ (corresponding $40 \mathrm{~mm}$ charring depth) which would be more appropriate for standard fire exposure.

Considering the actual difference of the char layer depth $(10 \mathrm{~mm})$ and of the charring depth $(42$ and $35 \mathrm{~mm})$ it can be assumed that the only varying parameter, the gas velocity, is finally responsible for the char oxidation and subsequently the smaller RCS. It is assumed that the actual gas velocity in combination with the oxygen content leads to glowing combustion which causes char contraction. It may be concluded that the effect is corresponding to an increased fire compartment temperature of up to $200^{\circ} \mathrm{C}$.

\section{ESTIMATION OF THE HEAT RELEASE BY THE TEST SPECIMEN}

When estimating the fire development in a compartment, the fire load of timber structures has moved into the focus of many authorities and researchers especially since solid timber products, e.g. CLT, appeared on the market. With the actual test set-up, it was possible to estimate the contribution of the test specimen by two alternative methods. Firstly, (A) based on the charring rate (charring depth), and secondly, (B) by means of the oxygen consumption.

\subsection{ESTIMATION OF THE HEAT RELEASE BY MEANS OF CHARRING $(\operatorname{Method~A)~}$}

Cone calorimeter tests have previously been conducted to determine the heat release rate of different materials under certain exposures of constant incident heat flux. In this test, a specimen is exposed to a homogeneous incident heat flux. It can be concluded that the following ratio is valid:

$\begin{array}{ll} & H R R: \beta=H R: d_{\text {char }} \\ \text { where } & \\ \text { HRR } & \text { is the heat release rate, } \\ \mathrm{HR} & \text { is the heat release, } \\ \beta & \text { is the charring rate and } \\ d_{\text {char }} & \text { is the charring depth. }\end{array}$

As a basis for a compartment fire model, a relationship between the charring rate and the heat release rate was determined from cone calorimeter test results. Investigations of heat release rates and corresponding charring were investigated in [7].

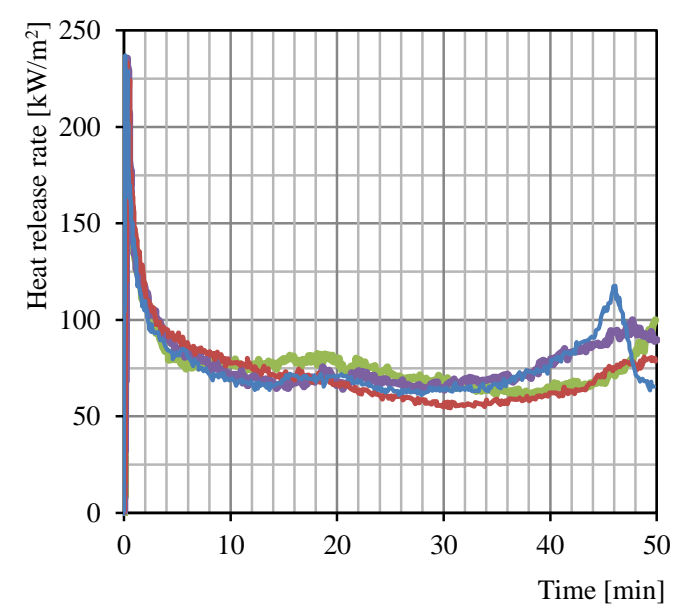

Figure 12: Heat release rate of untreated timber under $75 \mathrm{~kW} / \mathrm{m}^{2}$ exposure; reproduced from [7]

At $75 \mathrm{~kW} / \mathrm{m}^{2}$ incident radiant heat flux, a heat release of $5400 \mathrm{~kJ} / \mathrm{m}^{2}$ per millimetre of charring depth, for charring depths exceeding $10 \mathrm{~mm}$ was determined. Results are specified in Section 5.3.

\subsection{ESTIMATION OF THE HEAT RELEASE BY MEANS OF THE OXYGEN CONSUMPTION (Method B)}

The estimation of the heat release rate can be performed from the oxygen consumption using calorimetry [8]. It can be assumed that the heat release per consumed mass of oxygen is $13.1 \mathrm{MJ} / \mathrm{kg}$ for most bio-based materials. In the test setup, the oxygen concentration was measured in CS zero, A, B, C and D. Further, the gas velocity in the 
compartment was determined and was assumed to be constant. The mass of oxygen passing each section can be determined in a similar way as is done using a cone calorimeter. Results are specified in Section 5.3.

\subsection{RESULTS OF THE HEAT RELEASE ESTIMATION}

The calculated heat release rates according to the methods presented in Sections 5.1 and 5.2 are in rough agreement, see Figure 13. However, the results are not accurate enough to explain differences in heat release rates between tests, as indicated in Table 2 .

Table 2: Estimated heat release rate of Test $14(15 \mathrm{~m} / \mathrm{s}, 15 \%$ $\left.\mathrm{O}_{2}\right)$ and Test $09\left(3 \mathrm{~m} / \mathrm{s}, 15 \% \mathrm{O}_{2}\right)$

\begin{tabular}{|c|c|c|c|}
\hline \multirow{2}{*}{} & \multicolumn{3}{|c|}{ Heat release rate $\left(\mathrm{kW} / \mathrm{m}^{2}\right)$} \\
\cline { 2 - 4 } & \multicolumn{2}{|c|}{ Method 1 } & Method 2 \\
\cline { 2 - 4 } & Section B & Section C & Between section B and C \\
\hline Test 14 & 55.9 & 48.7 & 48.5 \\
\hline Test 9 & 44.5 & 52.7 & 61.7 \\
\hline
\end{tabular}

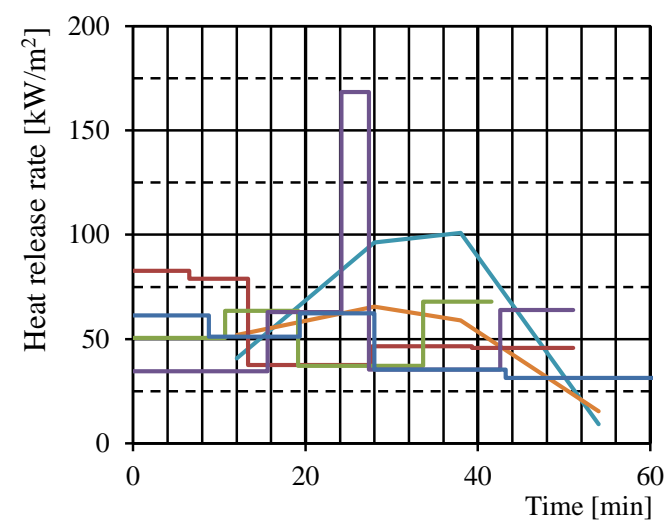

- between CS B and CS C (using calorimetry)

between CS A and CS B (using calorimetry)

- CS A (using charring rate)

CS D (using charring rate)

- CS C (using charring rate)

CS B (using charring rate)

Figure 13: Estimated heat release rates using method $A$ and $B$

\section{METHODS FOR SAMPLE GAS AND GAS VELOCITY ANALYSIS}

The study used redundant systems to determine the (i) gas velocity and the (ii) oxygen content.

The gas velocity was estimated using a Pitot tube [5] combined with a small thermocouple wire. Further, the gas velocity was determined using an anemometer at the gas inlet (after mixture of ambient air, oxygen and nitrogen) adding to the effect of the combustion gases of the Propane burners. The estimation was performed considering the thermal expansion of the gases. The latter was done using the gas temperature of the fire compartment. The combustion of Propane increased the inaccuracy as a combustion factor had to be introduced in order to take into account for the incomplete combustion. Differences between the calculation (anemometer) and more direct measurements (Pitot tube) were most visible at high gas velocities and can be specified to about $20 \%$. It was concluded that Pitot tube measurements are more reliable for measuring the gas velocity in fire compartments.

Compartment gas analysis was performed using a hand held electrochemical gas analyser and a paramagnetic method. The electrochemical gas analyser offered in-situ analysis of several parameters (gas types) which gave similar results $( \pm 1 \%)$ than the more expensive paramagnetic analysis which had to extract sample gas from the compartment. In contrast to cone-calorimetry, it seems that the electrochemical electrodes provide sufficiently accurate results for the test set-up presented here [9].

\section{DISCUSSION}

\subsection{Char contraction}

Earlier studies reported char contraction but the observed phenomenon could not be explained [10,11]. In contrast to these two studies, in this study char contraction was investigated in a closed compartment with a controlled gas flow. In this study, the boundary conditions in the combustion compartment were well defined. Results show that a variation of the fire compartment environment may lead to a char contraction of about $10 \mathrm{~mm}$ after $60 \mathrm{~min}$ which is in line to very recent studies [12].

Comparison (c), presented in Section 3.1.3, showed that a fire compartment oxygen content of $15 \%$ lead to char contraction while using oxygen content of 10 and $5 \%$ gave no significant effect. It seems like there is a limit for significant glowing combustion between 10 and $15 \%$. This is in line with another study of calorimetric experiments where the critical oxygen limit was found to be $14 \%$ [13].

For an oxygen content $15 \%$, the gas velocity influenced the char contraction, about $10 \mathrm{~mm}$ in difference, see Figure 9. This can be explained by the increased mass flow (turbulence) and thereby the enlarged transport of oxygen to the combustible specimen's surface. Thus, the temperatures in the virgin wood were different depending on the gas velocity as shown in Section 3.1.2. This is obvious by following the progression of the $300^{\circ} \mathrm{C}$ isotherm, assumed to be the char line [1], as shown in Figure 6.

Based on Comparisons (b) and (c), presented above, it seems that char contraction is rather a result of the gas velocity of a distinct concentration above a critical limit, than the oxygen content only. This explains, why no clear results were found in other studies where the boundary conditions were not sufficiently defined [10.11]. To assess the effect on timber member temperature of the char contraction (in combination with glowing combustion) simulations were performed, see Section 4. Simulations with standard fire exposure and char contraction (case (ii)) show that the char layer works as effective protection of the virgin wood. It was further shown (case (iii)) that the temperatures at the char line (target temperature $300^{\circ} \mathrm{C}$ at a depth of $40 \mathrm{~mm}$ as observed from the test results) would still be very low (ca. $180^{\circ} \mathrm{C}$ ) but glowing combustion induced by gas velocity accounts for the significant difference, see Figure 11. 
Two methods were used to estimate the heat release rate caused by the combustible test specimen in different testing environments. For cone calorimeter tests both test methods were compared in an earlier study [9]. The methods give results between ca. 45 and $60 \mathrm{~kW} / \mathrm{m}^{2}$, however, heat release rates over the time show considerable inconsistencies, see Figure 13. Further, an increased heat release rate for Test 14 where significant glowing combustion was determined (compared to Test 09, see Section 4) could not be confirmed, see Table 2 .

\section{CONCLUSIONS}

In the literature, the char layer development is considered to be a crucial part of analysis of timber members exposed to fire as it provides protection of the virgin wood. In more recent studies concerns are raised that the charring adds to the fire load when glowing. In this study, the focus was (a) the contribution of the char glowing combustion to the overall heat release and (b) the glowing effect on the residual cross section. In order to study these effects, the fire compartment environments were simulated by varying (i) the compartment temperature, (ii) the gas velocity and (iii) the oxygen content. In fires gas velocities up to $15 \mathrm{~m} / \mathrm{s}$ are reasonable while during a fully developed fire the oxygen content of the compartment gas is very low for ventilation controlled fires. However, as performance based design requires the consideration of an entire fire, the decay phase should also be considered.

In this study, it was proven that the temperature has a significant influence on the charring behaviour of a timber member. Moreover, it was shown that glowing combustion influences the char layer (char contraction) for oxygen contents above about $15 \%$. The effect becomes more significant when the gas velocity is increased.

Following this conclusion many fire resistance tests simulating entire including the cooling phase, may be questioned as the ventilation conditions (oxygen content, gas velocity) in the cooling phase were not controlled and not documented. Studies that have investigated different ventilation conditions are very rare but available literature indicate significant differences [14].

In performance based design, the char contraction may be taken into account in the decay phase depending on the ventilation conditions due to temperature differences, e.g. in stair cases.

Char contraction was estimated only after the test in lack of methodologies to measure this value during the test. Thus, it cannot be stated in which phase char contraction occurs. In future tests, the char contraction should be investigated further.

Considering the results presented for the heat release, no dependency on the glowing combustion of the timber member on the oxygen mass flow could be determined, see Table 2.

In future studies the methods presented in this paper should be improved the estimations of the heat release rate. Further, the time of heat exposure should be extended and the decay phase further evaluated.

\section{ACKNOLEDGEMENTS}

The authors want to acknowledge FORMAS who funded the study as well as the COST framework for support in general and the experts of COST FP1404 who organized the mini symposia at the WCTE 2016.

\section{REFERENCES}

[1] EN 1995-1-2: Design of timber structures - Part 1-2: General - Structural fire design, CEN, European Committee for Standardization, Brussels, 2004.

[2] EN 1363-1: Fire resistance tests - Part 1: General requirements, CEN, European Committee for Standardization, Brussels, 2012.

[3] Frangi, Andrea, and Mario Fontana. "Charring rates and temperature profiles of wood sections." Fire and Materials 27.2, 2003.

[4] Babrauskas, V., "Charring rate of wood as a tool for fire investigations." Fire safety journal 40.6. 2005.

[5] Heskestad, G. Bidirectional Flow Tube for Fire Induced Vent Flows, Appendix K in PA. Croce, and H. W. Emmons, eds. The Large-Scale Bed-Room Fire Tests, Factory Mutual Research, FMRC S/N 21011.4 (July 1974).

[6] Franssen, J. M. "User's manual for SAFIR 2011 a computer program for analysis of structures subjected to fire." University of Liege, Belgium, 2011.

[7] Crielaard, R. Self-extinguishment of crossLaminated timber. Diss. TU Delft, Delft University of Technology, 2015.

[8] Hugget, Clayton. Estimation of rate of heat release by means of oxygen consumption measurements. Fire and Materials. 4(2), pp.61-65. (1980).

[9] Nussbaum, R., "Oxygen Consumption Measurements in Cone Calorimeter", Fire and Materials. 11, 201-203 (1987).

[10] White, R.H., Charring rates of different wood species, $\mathrm{PhD}$, University of Wisconsin-Madison, Madison, Wisconsin, USA, 1988.

[11] Chatani, Y., Harada, K., Measurement of Char Oxidation of a Glue Laminated Timber Material heated by Cone Calorimeter, AOSFEST 2015, Tsuuba, Japan, 2015.

[12] Werther, N., Beitrag zu: Einflussgrössen auf das Abbrandverhalten von Holzbauteilen $u$ deren Berücksichtigung in empirischen und numerischen Beurteilungsverfahren, PhD Thesis, Technical University of Munich, Germany, 2016.

[13] Jervis, F. X., Application of fire calorimetry to understand factors affecting flammability of cellulosic material: Pine needles, tree leaves and chipboard, PhD Thesis, University of Edinburgh, UK, 2012.

[14] Kinjo, H., Yusa, S., Horio T., Hirashima T., Matsumoto, T., Saito, K., Fire Performance, Including the Cooling Phase, of Structural Glued Laminated Timber Beams. 8th International Conference on Structures in Fire. Shanghai, China, 2014. 